\title{
Bupivacaine as the Choice of Adjunctive Local Anaesthesia for Lower Third Molar Surgery Under General Anaesthesia: A Mini Review
}

\author{
Hilary Cheng* and Emilio Vazquez \\ Dental Core Trainee (Oral and Maxillofacial Surgery), Whipps Cross University Hospital, Leytonstone, London
}

Submission: December 22, 2019; Published: January 21, 2020

*Corresponding author: Hilary Cheng, Dental Core Trainee (Oral and Maxillofacial Surgery), Whipps Cross University Hospital, Leytonstone, E11 1NR, London

Abstract

Introduction: We describe the adjunctive use of local anaesthesia during surgical removal of lower third molars under general anaesthesia to manage postoperative pain. Our limited study shows that it is beneficial to administer a long-acting local anaesthetic such as bupivacaine with adrenaline for prolonged pain control.

Method: Eleven patients, requiring lower third molar extractions under general anaesthetic were included in this study. Parameters recorded were type, volume and concentration of local anaesthetic used +/- adrenaline as well as intraoperative analgesia prescribed by anaesthetist. All patients were administered bupivacaine by infiltration to the buccal and lingual vestibules in the anaesthetic preparation room immediately after induction and intubation. A pain questionnaire was filled by the patients a few days after their procedure.

Results: The overall low pain scores was low. A mean duration of postoperative anaesthesia was 9.4 hours. The average time to first rescue analgesic medication was 8.9 hours. The mean postoperative pain score was 3 after waking up from general anaesthesia and 5 after the anaesthetic effects of bupivacaine had worn off. Three patients did not require postoperative analgesic medication.

Conclusion: Bupivacaine with adrenaline provides excellent prolonged postoperative pain control and analgesia following surgical removal of lower third molars for up to twelve hours. The duration of anaesthetic effect is prolonged by the addition of epinephrine 1:200,000 [1]. Hence, the time to rescue analgesic medication is much longer and the need for analgesia is reduced [1,2]

\section{Introduction}

Local anaesthesia and pain management are the most important tenets in any oral surgical procedure [2,3]. Effective pain control in a surgical procedure facilitates patient cooperation and reduces patient anxiety $[2,4]$. The choice of local anaesthetic with or without a vasoconstrictor depends on the length of the dental procedure and weighed against the onset and duration of action of the local anaesthetic [2,3]. The adjunctive use of local anaesthesia during surgical removal of lower third molars under general anaesthesia (GA) is commonly used to manage postoperative pain [4-6]. Furthermore, the use of a long-acting local anaesthetic such as bupivacaine with adrenaline prolongs pain relief [2,6-8]. The purpose of this article is to discuss the benefit of adjunctive bupivacaine with adrenaline in lower third molar surgery under general anaesthesia.

\section{Method}

Eleven medically fit patients (Table 1), requiring lower third molar extractions under general anaesthetic were included. No alterations were made to the treatment plan, local anaesthetic or operative technique for the purpose of this article. Parameters recorded were type, volume and concentration of local anaesthetic used $+/$ - adrenaline as well as intraoperative analgesia prescribed by anaesthetist. All patients were administered bupivacaine as infiltrations in the buccal and lingual vestibules via $2 \mathrm{ml}$ syringes with a 23 Gauge needle (23G Hypo Needle Safety BD Eclipse) and $0.5 \mathrm{ml}$ Insulin Syringes (BD Microfine Plus Demi $0.5 \mathrm{ml}$ Insulin Syringe $29 \mathrm{Gx} 12.7 \mathrm{~mm}$ ). The local anaesthetic was administered in the anaesthetic preparation room immediately after induction and intubation. The patients were called a few days after their procedure to fill a pain questionnaire (Figure 1) with consent. 
The visual analogue scale was used to help the patient decide their postoperative pain score (Table 2). Patients were also asked their duration of anaesthesia as well as time to their first rescue analgesic medication.

1. How would you rate your pain using the below image when you woke up from general anaesthesia?

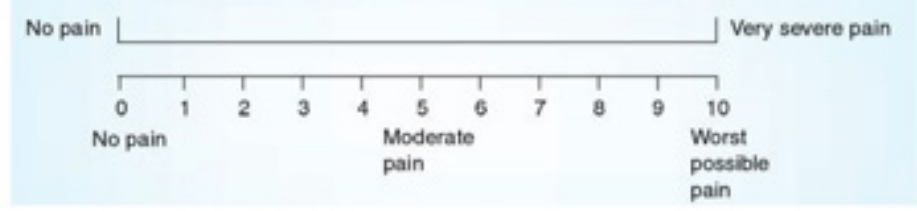

2. How long after your operation did your numbness wear off? (Please circle)

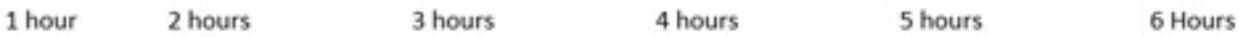

3. How would you rate your pain using the below image after the numbness wore off?

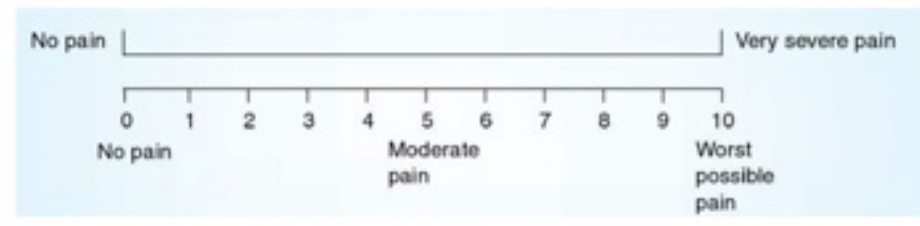

4. How long after the operation did you start taking your painkillers? (Please circle)

1 hour 2 hours 3 hours 4 hours 5 hours 6 Hours

Figure 1: Pain questionnaire.

Table 1: Data Collection sheet for each case.

\begin{tabular}{|c|c|c|c|c|}
\hline Case & Patient Demographics & Procedure under GA & Local Anaesthetic Used & Intraoperative Analgesia \\
\hline 1 & $\begin{array}{c}\text { Male, } 51 \text { years old, American } \\
\text { Society of Anaesthesiologists } \\
\text { Classification (ASA) } \\
1\end{array}$ & $\begin{array}{l}\text { Extraction of Lower right third molar } \\
\text { (LR8) }\end{array}$ & $\begin{array}{l}5 \mathrm{ml}, 0.25 \% \text { bupivacaine, } \\
1: 200,000 \text { adrenaline }\end{array}$ & $\begin{array}{l}\text { Fentanyl } 100 \mathrm{mg} \\
\text { Paracetamol } 1 \mathrm{~g} \\
\text { Diclofenac } 75 \mathrm{mg}\end{array}$ \\
\hline 2 & Female, 29 years old, ASA 1 & $\begin{array}{l}\text { Extraction of LR8 and lower left third } \\
\text { molar (LL8) }\end{array}$ & $\begin{array}{l}10 \mathrm{ml}, 0.5 \% \text { bupivacaine, } \\
1: 200,000 \text { adrenaline }\end{array}$ & $\begin{array}{l}\text { Fentanyl } 100 \mathrm{mg} \\
\text { Paracetamol 1g } \\
\text { Diclofenac } 75 \mathrm{mg}\end{array}$ \\
\hline 3 & Female, 18 years old, ASA 1 & Extraction of LR8 & $\begin{array}{l}3 \mathrm{ml}, 0.5 \% \text { bupivacaine, } \\
1: 200,000 \text { adrenaline }\end{array}$ & $\begin{array}{l}\text { Fentanyl } 100 \mathrm{mg} \\
\text { Paracetamol 1g } \\
\text { Diclofenac } 75 \mathrm{mg}\end{array}$ \\
\hline 4 & Male, 27 years old, ASA 1 & $\begin{array}{c}\text { Extraction of LR8, LL8, upper right third } \\
\text { molar (UR8), upper left third molar } \\
\text { (UL8) }\end{array}$ & $\begin{array}{l}10 \mathrm{ml}, 0.5 \% \text { bupivacaine, } \\
1: 200,000 \text { adrenaline }\end{array}$ & $\begin{array}{l}\text { Paracetamol } 1 \mathrm{~g} \\
\text { Fentanyl } 100 \mathrm{mg} \\
\text { Morphine } 4 \mathrm{mg}\end{array}$ \\
\hline 5 & Male, 25 years old, ASA 1 & Extraction of LR8, LL8, UR8, UL8 & $\begin{array}{l}10 \mathrm{ml}, 0.5 \% \text { bupivacaine, } \\
1: 200,000 \text { adrenaline }\end{array}$ & $\begin{array}{l}\text { Morphine } 5 \mathrm{mg} \\
\text { Paracetamol 1g } \\
\text { Diclofenac } 75 \mathrm{mg} \\
\text { Fentanyl } 100 \mathrm{mcg} \\
\end{array}$ \\
\hline 6 & Male, 30 years old, ASA1 & Extraction of LR8, LL8, UR8, UL8 & $\begin{array}{l}14 \mathrm{ml}, 0.5 \% \text { bupivacaine, } \\
1: 200,000 \text { adrenaline }\end{array}$ & $\begin{array}{l}\text { Morphine 5mg } \\
\text { Paracetamol 1g } \\
\text { Diclofenac } 75 \mathrm{mg} \\
\text { Fentanyl } 100 \mathrm{mcg}\end{array}$ \\
\hline 7 & Male, 22 years old, ASA 1 & Extraction of LR8, LL8 & $\begin{array}{l}8.5 \mathrm{ml}, 0.5 \% \text { bupivacaine, } \\
1: 200,000 \text { adrenaline }\end{array}$ & $\begin{array}{c}\text { Paracetamol 1g } \\
\text { Remifentanil infusion } \\
(0.1 \mathrm{micrograms} / \mathrm{kg} / \mathrm{min})\end{array}$ \\
\hline 8 & Male, 17 years old, ASA 1 & Extraction of LR8, LL8 & $\begin{array}{l}9 \mathrm{ml}, 0.5 \% \text { bupivacaine, } \\
1: 200,000 \text { adrenaline }\end{array}$ & $\begin{array}{c}\text { Paracetamol 1g } \\
\text { Remifentanil infusion } \\
(0.1 \mathrm{micrograms} / \mathrm{kg} / \mathrm{min})\end{array}$ \\
\hline
\end{tabular}




\begin{tabular}{|c|c|c|c|c|}
\hline 9 & Female, 22 years old, ASA 1 & Extraction of LR8, LL8, UR8, UL8 & $\begin{array}{c}8 \mathrm{ml}, 0.5 \% \text { bupivacaine, } \\
1: 200,000 \text { adrenaline }\end{array}$ & $\begin{array}{c}\text { Paracetamol 1g } \\
\text { Morphine } 5 \mathrm{mg} \\
\text { Diclofenac } 75 \mathrm{mg} \\
\text { Remifentanil infusion } \\
(0.1 \mathrm{micrograms} / \mathrm{kg} / \mathrm{min})\end{array}$ \\
\hline 10 & Female, 43 years old, ASA 1 & Extraction of LR8, LL8, UL8 & $\begin{array}{c}8 \mathrm{ml}, 0.5 \% \text { bupivacaine, } \\
1: 200,000 \text { adrenaline }\end{array}$ & $\begin{array}{c}\text { Paracetamol 1g } \\
\text { Diclofenac } 75 \mathrm{mg} \\
\text { Remifentanil infusion } \\
(0.1 \text { micrograms } / \mathrm{kg} / \mathrm{min}) \\
\text { Fentanyl } 100 \mathrm{mcg}\end{array}$ \\
\hline 11 & Female, 34 years old, ASA 1 & Extraction of UL8, LL8 & $\begin{array}{l}8 \mathrm{ml}, 0.5 \% \text { bupivacaine, } \\
1: 200,000 \text { adrenaline }\end{array}$ & $\begin{array}{c}\text { Paracetamol 1g } \\
\text { Remifentanil infusion } \\
\text { (0.1micrograms } / \mathrm{kg} / \mathrm{min})\end{array}$ \\
\hline
\end{tabular}

\section{Results}

The results of our questionnaire (Table 2) showed that bupivacaine has a long duration of anaesthesia and time to first rescue analgesic medication. A mean duration of postoperative anaesthesia was 9.4 hours. The average time to first rescue analgesic medication was 8.9 hours. The mean postoperative pain score was 3 after waking up from general anaesthesia and 5 after the anaesthetic effects of the bupivacaine had worn off. Three patients did not require postoperative analgesic medication. All cases requiring the lower third molars to be removed surgically involved bucco-gingival incisions prior to raising mucoperiosteal flaps, bone removal, sectioning of teeth with burrs and repair of incisions with absorbable sutures.

Table 2: Table of results.

\begin{tabular}{|c|c|c|c|c|}
\hline Case & Pain score from Q1 & Hours from Q2 & Pain score from Q3 & Hours from Q4 \\
\hline 1 & 4 & 12 & 9 & 8 \\
\hline 2 & 0 & 10 & 3 & 8 \\
\hline 3 & 0 & 12 & 5 & No painkillers required \\
\hline 4 & 0 & 6 & 1 & 12 \\
\hline 5 & 4 & 12 & 6 & 6 \\
\hline 6 & 5 & 12 & 6 & No painkillers required \\
\hline 7 & 0 & 6 & 8 & 8 \\
\hline 8 & 6 & 12 & 8 & 5 \\
\hline 10 & 10 & 6 & 5 & No painkillers required \\
\hline
\end{tabular}

\section{Discussion}

The long-acting amide local anaesthetic bupivacaine does provide excellent surgical anaesthesia and extended postoperative analgesia [1,2,6-9]. Our limited study shows that bupivacaine with adrenaline provides prolonged postoperative pain control and analgesia in the surgical removal of lower third molars for up to twelve hours $[7,8]$. It is believed bupivacaine with adrenaline reduces analgesic requirements and delays the initial request for postoperative analgesia in the early postoperative hours when the maximum pain intensity is reached $[1,7,8]$. The addition of adrenaline to bupivacaine have several benefits including a decrease in the peak plasma concentration of the local anaesthetic agent, increase in the duration and the quality of anaesthesia, reduction of the minimum concentration of anaesthetic needed for nerve block, and reduction of blood loss $[3,5,9]$. Our patients had mild pain or no pain after waking up from general anaesthesia. The onset of action of bupivacaine is approximately 2 to 10 minutes and anaesthesia may last two or three times longer than lidocaine and mepivacaine $[1,9]$. The administration of local anaesthetic infiltrations in the anaesthetic preparation room allows time to facilitate maximal anaesthetic effect before the surgical procedure is commenced. The volume of local anaesthetic required is low, demonstrating high anaesthetic potency and efficacy $[6,8]$. The duration of anaesthetic effect is prolonged by the addition of epinephrine 1:200,000 [9]. Hence, the time to rescue analgesic medication is much longer and the need for analgesia is reduced [1,9]. The overall pain scores were found to be low. The increased duration of action of bupivacaine to modify postoperative pain after surgical removal of lower third molars has allowed our patients wake up in a pain-free, relaxed manner. The use of intraoperative analgesics by the anaesthetist under general anaesthetic is considered the norm. It was noted 
by one anaesthetist, that there was a significant reduction in pain stimulation from the patients under general anaesthesia due to the high anaesthetic potency and efficacy of $0.5 \%$ bupivacaine 1:200,000 adrenaline [6,7]. This, in turn, facilitated a dose reduction in intraoperative remifentanil for some patients. None of our patients experienced complications owing to the long duration of effective local anaesthesia.

\section{Conclusion}

Several factors are responsible for the efficacy of local anaesthesia. There are multiple factors such as technique variability, route of administration, anatomical variations, pain threshold, complexity of the procedure, and reporting error [10]. There are only a handful of studies in the literature assessing the efficacy of bupivacaine in the surgical removal of lower third molars [6,9]. Our observations confirm that the use of bupivacaine provides profound local anaesthesia, lack of adverse reactions, and increased duration of action $[1,8]$. We therefore conclude that adjunctive bupivacaine $0.5 \%$ with $1: 200,000$ epinephrine is highly effective in controlling perioperative and postoperative pain after the surgical removal of lower third molars under general anaesthesia $[4,6]$. Further long-term randomised controlled trials are required to underscore clinical efficacy of bupivacaine and motivate its continued use and evaluation in oral and maxillofacial surgery.

\section{References}

1. (2019) (FDA) Bupivacaine $\mathrm{HCl}$ Rx only, $0.5 \%$ with epinephrine 1:200,000 (as bitartrate) (bupivacaine hydrochloride and epinephrine injection, USP).

2. Milam SB, Giovannitti JA (1984) Local anesthetics in dental practice. Dent Clin North Am 28(3): 493-508.

3. Grevers G, Ledderose H(1996) Local anesthesia in operations of the head-neck area. Laryngorhinootologie 75(7): 433-436.

4. Parekh S, Gardener C, Ashley PF, Walsh T (2014) Intraoperative local anaesthesia for reduction of postoperative pain following general anaesthesia for dental treatment in children and adolescents. Cochrane Database Syst Rev (12): Cd009742.

5. Sisk AL (1992) Vasoconstrictors in local anesthesia for dentistry. Anesth Prog 39(6): 187-193.

6. Moore PA (1984) Bupivacaine: a long-lasting local anesthetic for dentistry. Oral Surg Oral Med Oral Pathol 58(4): 369-374.

7. Moore DC, Bridenbaugh LD, Thompson GE, Balfour RI, Horton WG (1978) Bupivacaine: A Review of 11,080 Cases. Anesth Analg 57(1): 42-53.

8. Babst CR, Gilling BN (1978) Bupivacaine: a review. Anesth Prog 25(3): 87-91.

9. Balakrishnan K, Ebenezer V, Dakir A, Kumar S, Prakash D (2015) Bupivacaine versus lignocaine as the choice of locall anesthetic agent for impacted third molar surgery a review. J Pharm Bioallied Sci 7(Suppl 1): 230-233.

10. Budenz AW (2008) Selection factors for local anesthetic agents. J Calif Dent Assoc 36(10): 735-738.

This work is licensed under Creative Commons Attribution 4.0 License

DOI: $10.19080 / J A I C M .2020 .10 .555782$ 